\title{
Breast cancer in the elderly
}

\author{
Chibundu E Ohanaka
}

\begin{abstract}
Between January 1997 and December 2001, 107 patients were admitted and treated for breast cancer at the University of Benin Teaching Hospital, Nigeria. Of these, 27 $(25.2 \%)$ were aged 60 years and above, all females, mean age 66.3 years. Only two patients (7.4\%) presented with early breast disease (stages I and II), the rest presented with late disease (stages III and IV). Duration of symptoms before presentation was between six weeks and three years (mean 15 months). Histology in all cases revealed invasive ductal carcinoma ranging from the well differentiated to the poorly differentiated varieties. Twenty patients had mastectomy, while seven had radiotherapy. All patients had adjuvant chemotherapy and tamoxifen. Eight patients (29.6\%) were lost to follow-up. Of the remaining 19 patients, $10(52.6 \%)$ were officially recorded to have died within the period under review. Health education of the elderly and physician vigilance are keys to early detection and treatment of breast cancer in the elderly.
\end{abstract}

\section{INTRODUCTION}

Breast cancer is a universal problem.1,2,3 In Nigeria, it is the most common female surgical cancer and it has indeed surpassed cancer of the cervix as the commonest cancer in females. ${ }^{4,5}$ In sub-Saharan Africa, it occurs in younger individuals with peak incidence about a decade earlier when compared with developed countries. ${ }^{3}$ Consequently, more emphasis is laid on the early detection of breast cancer in the younger age groups with less emphasis on the elderly. Breast cancer has, however, been found to be a serious disease in terms of incidence and mortality in older women. ${ }^{6,7}$

Studies carried out in advanced countries regarded the elderly as those aged 65 years and above. ${ }^{8,9}$ This study, however, regards the reference age of the elderly as 60 years and above. The lower figure is due to the fact that

KEY WORDS: Breast cancer, elderly, Nigeria

Consultant Surgoon/Senior Locturer, Department of Surgery, University of Benin Teaching Hospital, PMB 1111, Benin City, Nigeria. Tel: 052-602420 E-mail: cohanaka@vahoo.com

( ) CMS UNIBEN JMBR 2002; 1(1): 39-42 life expectancy is significantly lower in Nigerian women as compared to Caucasians. Recent World Health Organization report puts the average life expectancy for Nigerian females at 48.2 years. $^{10}$

Several studies have been carried out to determine the pattern of breast cancer in elderly women, but there is a dearth of reports on this issue from Africa. This paper, therefore, aims at highlighting the problem in Nigeria. This will contribute towards raising awareness on the magnitude of breast cancer in this often neglected age group. It will also assist health planners in formulating policies aimed at reducing the morbidity and mortality associated with breast cancer in the elderly.

\section{PATIENTS AND METHODS}

This is a retrospective study involving all patients above the age of 60 who were admitted and managed for breast cancer in the University of Benin Teaching Hospital over a fiveyear period (January 1997-December 2001). Those who were seen at the surgical outpatients but not admitted and those below the age of 60 were excluded from the study. 
40 Joumal of Modicine and Biomedical Research

Information gathered from the hospital records included age, sex, duration of symptoms, stage at presentation, histology and treatment administered. A similar record of all deaths due to cancer of the breast over the period of study was reviewed. From this, the elderly patients who died of this disease were identified.

\section{RESULTS}

Within the five-year period, 107 patients were admitted and managed for breast cancer at the University of Benin Teaching Hospital, Nigeria. There was only one male patient. Of the $107 \mathrm{pa-}$ tients, $27(25.2 \%)$ were aged 60 and above and, therefore, satisfied the criteria for inclusion in the study. The aye range was $60-83$ years (mean 66.3 years). The age distribution is as shown in Table 1.

As regards the clinical stage of the disense at presentation, only two patients (7.4\%) presented with early breast disease (stages I and II). All the others were seen with late disease (stages III and IV). The duration of symptoms before presentation ranged from three weeks to three years (mean 15 months).

\section{Table 1: Age distribution of breast cancer in the eldorly}

\begin{tabular}{lcr}
\hline Age group (years) & Numbor & Purcentage \\
\hline $60-64$ & 14 & 51.9 \\
$65-69$ & 7 & 25.9 \\
$70-74$ & 2 & 7.4 \\
$75-79$ & 2 & 7.4 \\
$80-84$ & 2 & 7.4 \\
85 and above & - & - \\
\hline Total & 27 & 100 \\
\hline
\end{tabular}

Histologically, all the patients had invasive duct carcinoma ranging from the well differentiated to the poorly differentiated varieties. Even the patients that presented clinically as Paget's disease had an underlying invasive duct carcinoma. Of all the patients involving all age groups seen within this period with breast cancer only one 60-year-old woman presented with bilateral disease. Histology revealed invasive duct carcinoma in both breasts.
With respect to treatment, 20 patients had one form of mastectomy while all the patients had chemotherapy. Neoadjuvant chemotherapy was routinely employed in all patients who presented initially with inoperable breast cancer. Those who eventually had surgery continued with cyclical chemotherapy. The FAC regime (5fluorouracil, adriamycin and cyclophosphanide) was used. All the patients had tamoxifen but only seven had radiotherapy.

Eight patients (29.6\%) were lost to follow-up. Of the remaining 19 patients, $10(52.6 \%)$ were officially recorded to have died within the period under review.

\section{DISCUSSION}

Incidence of breast cancer in the elderly in our study was $25.2 \%$, lower than figures quoted from developed countries where this group of patients constitute about half of the cases seen. ${ }^{0,11,12}$ This is despite the lower reference age of 60 used to define the elderly, as opposed to the latter studies that used a higher age (65 years). The disparity could be explained by the fact that breast cancer is known to occur in the younger age group in our environment when compared with developing countries. ${ }^{3}$ Also contributory to the relative paucity in the older age group is the reduction in life expectancy in our environment ( 48.2 years for females) sequel to the ever-dwindling socio-economic standards. The fact that about half of our patients fell within the 60-64 years age category and none above 85 years shows that breast cancer remains a disease of the relatively young in our environment.

It is generally known that a great majority of our patients with breast cancer present late. ${ }^{13}$ Our study, however, showed that the elderly patients presented with more advanced stages of cancer than their younger counterparts. There is a controversy regarding the stage at which elderly women present with breast cancer. Whereas some authors believe that they are first seen at a later stage ${ }^{14}$, others have shown that early breast cancer is equally common in all age groups ${ }^{9}$. The major factor's contributory to this state of affairs in our environment is ignorance, which rosults in late presentation. The mean duration of symptoms of 15 months is an eloquent testimony to the degree of late presentation in our 
patients. Generally, there is a lack of awareness, as health education in relation to breast disease is usually targeted at the younger more vulnerable age group. Elderly women are therefore not aware of the importance of self-examination of the breast in the early detection of breast lumps. As a result of their poor educational background and traditional beliefs, they are reluctant to reveal their breast problems to even close relatives for fear of being taken to the hospital for treatment. They seem to be more comfortable with traditional healers and spiritualists due to the erroneous belief that mastectomy is the sole treatment for all breast ailments irrespective of the nature.

Infiltrative ductal carcinoma remains the most common breast cancer pathology even in elderly women. ${ }^{15,16}$ This was equally our experience in this study. The two odd patients that presented with bilateral breast cancer and Paget's disease of the breast had invasive ductal carcinoma.

The current management of breast cancer tends towards more conservative treatment. ${ }^{9} \mathrm{Re}$ cent evidence suggests that older women may even have a particularly low rate of recurrence after lumpectomy and radiotherapy compared with their younger counterparts. ${ }^{17}$ Most of our patients, however, presented late and were thus not eligible for more conservative therapy. Mastectomy in our patients was mainly aimed at reducing their tumour burden. For example, of all the patients in our study, only the two with early disease could be said to have received curative mastectomy. In all others it was palliative. Preoperative neoadjuvant chemotherapy was employed because it has been found to be effective in down-staging primary tumours and, moreover, is able to prevent advancing metastatic growth early in the course of the disease. ${ }^{18,19}$

Tamoxifen alone as a first line treatment has been found to be useful in the management of frail elderly women who may not be able to vithstand surgery due to co-morbid factors. ${ }^{20,21}$ We routinely commence our patients on tamoxifen as soon as the diagnosis is confirmed. iirtually all patients are referred for palliative adiotherapy but only the few who can afford the financial involvement usually benefit from :t. Our mortality figure of $52.6 \%$ is likely to be naccurate. The figure could be higher, as it was zalculated from those who were successfully folsowed up. The actual mortality is difficult to compute in an environment where no eyebrows are raised when a patient dies outside the hospital.

In general, the key to reducing morbidity and mortality following breast cancer lies in its early detection. This is even more relevant in the elderly who present with special management problems as a result of old age. A mean duration of symptoms prior to presentation of 15 months emphasises the need for measures to be taken in order to encourage early detection.

Screening mammography has been found to be particularly effective in detecting breast cancer in elderly women. ${ }^{11,21}$ This facility is, however, not readily available in our environment. The only available option lies in health education including teaching the principles of breast self-examination to women. Unfortunately, the elderly in our society who are usually illiterate and reside in the rural communities may not be reached during public health campaigns. It is therefore advocated that community health workers should be made to reach these patients wherever they are. Similarly, young ladies who have benefited from health education should be encouraged to help disseminate the information to their mothers and other close relatives particularly those in the rural areas. It is also being advocated that doctors should be encouraged to routinely examine the breasts of elderly patients whenever they come up with even' unrelated health problems. These measures will go a long way in helping with the early diagnosis of breast cancer in elderly women.

\section{References}

1. Celko CM. Breast cancer epidemiology in Czech Republic. Cent Eur J Pub Health 1996; 4(2): 106-9.

2. Saunders C, Vijay V, Stein J and Baum M. Setting up a breast cancer family history clinic. Ann R Coll Surg Eng 1999; 81(6): 393-8.

3. Anim JT. Breast cancer in sub-saharan African women. Afr JMed Meal Sci 1993; 22(1): 5-10.

4. Olanaka CE and Ofoegbu RO. The pattern of surgical cancers in Nigeria: the Benin experience. Trop Doctor 2002; 32: 2-3.

5. Adebamawo $\mathrm{CA}$ and Ajayi $\mathrm{OO}$. Breast cancer in Nigeria. West Afri J Med 2000; 19(3): 179-191.

6. Yancik R, Ries LG and Yates JW. Breast cancer in aging women. A population-based study of contrasts in stage, surgery and survival. Cancor 1989; 63: 976-980. 
42 Joumal of Medicine and Biomedical Research

7. Rimer BK. Improving the use of cancer screening for older women. Cancer 1993: 72(Suppl. 3): 1084-7.

8. Morrow M. Breast disease in elderly women. Surg Clinc NAmer 1994; 74(1): 145-161.

9. Law TM, Hesketh PJ, Porter KA, Lawn-Tsao L, McAnaw R and Lopez MJ. Breast cancer in elderly woinen. Surg Clin NAmer 1996; 76(2): 289-308.

10. WHO. Basic indicators for all member states. In: The World Health Report 2000. Geneva: World Health Organization.

11. Adami HO, Malker B and Holmberg L. The relation between survival and age at diagnosis in breast cancer. $N$ Engl J Med 1986; 315: 559.

12. Thomas LR, Rox SA, Leake BG and Roetzheim RG. The effects on health beliefs on screening mammography utilisation among a diverse sample of older women. Women Heallh 1996; 24(3): 77-94.

13. Adebamawo CA and Adekunle OO. Case controlled study of the epidemiological risk factors of breast cancer in Nigeria. Br J Surg 1999; 86: 665-668.

14. Goodwin JS, Samet JM and Key CR. Stage at diagnosis of cancer varieties with the age of the patient. J Am Geriatr Soc 1986; 34: 20.

15. Bernado G, Plastina B and Stada M. Breast cancer in elderly patients: our experience about some features. Ann Oncol 1994; 5(Suppl 8): 59.

16. Swanson R, Sawicka J and Wood W. Treatment of carcinoma of the breast in the older geriatric patient. Surg Gynaecol Obstetr 1991; 173: 465.
17. Fourquet A, Campara F and Zafiani B. Prognostic factors of breast recurrence in the conservative management of early breast cancer. A 25year follow-up. Int J Radiat Oncol Biol Phys 1989; 17: 719-725.

18. Carnso G Cucciarres, Lo-Bello M, Mercurio G, Candela F, Ciauchino C and Lagalla R. Neoadjuvant intralesionsl chemotherapy for breast neoplasm in advanced stages assessment of its efficacy with doppler color. Radiol Med Torino $1995 ; 89(5)$ : 613-8.

19. Wenzel C, Schmidinger M, Locker GJ, Taucher S, Gnant M, Jakesz R and Steger GG. Clinical phase II - evaluation of neoadjuvant, cytostatic combination chemotherapy with docetaxel and epidoxombicin in female breast cancer patients. Wien Klein Wochenschr 1999; III(20): 843-50.

20. Auclero C, Khayat D and Borel C: Tamoxifen as sole treatment in patients aged 65 and over with primary breast cancer. Proc Nalt Soc Clin Onod 1990; 9: A 173.

21. Talk GL, Gioymue-Jones D and Gray JG. Efficacr tamoxifen as the primary treatment of oporab!e breast cancer in the ligh risk patient. Aust NZ. Surg 1989; 59: 543-545.

22. Adderley-Kelly and Green P M. Breast cance education, self efficacy and screening in olde African American wpmen. I Natt Black Nurses Assoc 1997; 9(1): 45-57. 